\title{
Influence of Physical Exercise on Sexual Activity: the Case of Practitioners of Physical Activities and Sports in the City of Douala
}

\author{
Emmanuel Noel ESSOMBA ${ }^{1 *}$, Dieudonné ADIOGO ${ }^{1}$, Hervé MOBY $^{1}$, Audrey NGUENG ${ }^{1}$, \\ Madeleine Irma NGWE ${ }^{1}$, Malea NGANDE ${ }^{1}$, Yves COPPIETERS ${ }^{2}$ \\ ${ }^{1}$ Faculty of Medicine and Pharmaceutical Sciences-Douala, University of Douala-Cameroon \\ ${ }^{2}$ Ecole de Santé Publique, Université Libre de Bruxelles (ULB), Bruxelles, Belgique
}

\begin{abstract}
Introduction: The contribution of physical activity on sexual activity seems to be controversial. The objective of this study was to assess the influence of physical activity on the sexual activity of practitioners of physical activity and sports in the city of Douala. Material and method: This was a cross-sectional and analytical study carried out from February to May 2014. The changes in sexual habits were determined by comparing the number of intercourse and sexual performance, before and after the beginning of the sport's practice. The Chi2 test and multivariate logistic regression were used for the associations. Results: Overall, 370 subjects were interviewed. The average age was $30.1 \pm 7.73 a n s$. An increase in sexual performance was observed in all participants.The rate of increase of the refractory period was on average higher among practitioners of sport $(p=0.03)$. Multi-varied logistic regression introduced a strong correlation between the age group [35-45] [OR $=0$. 37; CI at95\% of OR=0.37 - 0.87; $P=0.002]$, the male sex [OR =

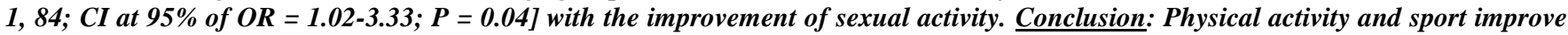
sexual activity at any age. Physical activity and sport practice presents itself as a part of the solution to sexuality issues. Because of its positive effect on the prevention of chronic disease and its influence on some determinants of health, his practice should be widely encouraged.
\end{abstract}

Keywords: sport; sexual activity; improvement; Afr

\section{Introduction}

Physical exercise is the realization of movements of the body and its parts by means of muscular contractions resulting in a muscle energy expenditure greater than the expense of energy at rest [1]. It is often confused with the term sport and in this orientation,physical exercise includes all physical activities and sports activities with specific objectives for each category. The health benefits due to physical exercise havebeen formally recognized [2]. In general, the practice of physical exercise allows fora better performance of the heart and blood vessels, promoting irrigation of all muscles, including those of the sexual organs which are solicited during sexual activity [3].

Sexual activity is governed by sexual intercourse, the induction of which is due to organic or behavioral stimuli. It has asobjective the occurrence of orgasm i.e. the climax point of sexual excitement [4]. It is considered as one of the main bases of a couple's relationship. It is in this sense that if affected, sexual activity has negative effects on couples and families [5]. The absence of sexual activity or any dysfunction in a relationship results, especially for men,ina decreaseof self-esteem and an inferiority complex that affect his behavior in the society [6]. These concern, very often, lead men to seek in pharmacies,drugs which stimulate sexual activity such as Sildenafil, indicated for erectile dysfunctions whichwould have aphrodisiac and stimulating properties and results to more frequent sexual intercourse of longer duration characterized by short refractory period synonymous to an improved sexual performance [6].
According to some researchers, exercise acts at the same time on both the physical appearance and the mental state [7]. The fact of being more relaxed, slimmer, muscular, and more comfortable in your body, to be more attractive, improves self-confidence, which would enrich sexual life. Also the fact to have a greater cardiovascular endurance and a better muscle tone would constitute assets during a sexual relationship [8].

This suggests that sexual activity would be boosted by physical exercise and therefore practitioners of physical exercises would be more fitted to have a fulfilled, and even more intense sexual activity. [7].

Studies relating the practice of physical activity, sports and the quality of sexual life in Canada and the United States, reported a controversy that, according to the exercised discipline, its duration and its frequency, sexual activity can be boosted or weakened [3]. Researchers in Massachusetts had scrutinized the sexual habits of 160swimming coaches, men and women aged 50 to 70 years. These people, in great shape, swam on average an hour a day, four to five times per week. The analysis of the results showed that these men and women knew a sexual life similar to that of people aged 2030 years old [7]. In another study involving 25 women, the frequency of sexual activity rose by $30 \%$ as a result of a program of aerobics dance ofthree months [7].On the other hand, another study presents an overdose of physical activity as an aphrodisiac. This is the case of adepts of marathon which exceed $25 \mathrm{~km}$ of training per day [8].

Regarding Africa in general, and Cameroon in particular, studies on this topic are rare. The hypothesis, according to 


\section{International Journal of Science and Research (IJSR) \\ ISSN (Online): 2319-7064 \\ Index Copernicus Value (2013): 6.14 | Impact Factor (2015): 6.391}

which physical exercise would have an impact on sexual activity on the people described as sexually "hot", seems not to be confirmed.That is why this preliminary work was carried out on Cameroonian practitioners of physical activities and sportsin thecity of Douala. It helps to determine following the age, sex and type of activity, the effects of the practice of physical exercise on the quality of their sexual activity. The results of this work have enabled us to inform on one of the means which would promote the maintenance of a good state of health, the improvement of self-respect, the improvement of the quality of sexual activity, the improvement of the erectile functionfor strengthening relationships of couples.

\section{Methods}

\section{Type and period of the study}

It was an analytical, cross-sectional and prospective study which took place over a period of six months, from January to June 2014.

\section{Scope of the Study}

The study was conducted in the city of Douala. Economic capital of Cameroon, main business center, Douala is the capital of the Littoral region. There are six districts composed of about 150 neighborhoods, distributed on an area of $923 \mathrm{~km} 2$. Douala is a mosaic of the various ethnic groups of all the regions of Cameroon and counts approximately 2,446,945 inhabitants, with a density of 2,651 inhabitants per $\mathrm{Km}^{2}$ [9]. The adult population of this city in particular as that of Cameroon in general, is exposed to the risk factors of cardiovascular disease.

An epidemiological study on obesity at workplace in the city of Douala showed an overall prevalence of obesity of 36.1\% for women and $17.8 \%$ for men [9]. Another study on the screening of cardiovascular disease among students of the University of Douala and the influence of physical and sport activities, showed that $12.7 \%$ of the participants had a blood pressure (BP) greater or equal 140/90 mm Hg, 3.6\% were obese and $0.9 \%$ had a blood glucose levels greater than or equal to $1.26 \mathrm{~g} / \mathrm{L}$ [10]. In front of these diseases, sports and physical activity presented positive effects on the prevention and reduction of their risk factors [11]. At Douala, populations found themselves in spaces adapted or not for the practice of sport, depending on the physical capacities and specific individual objectives. They gather for jogging, walking, fitness sports or, for a few minutes to few hours of football, basketball, handball, tennis and other sport.The study was conducted in places open for sport practice in this city. Sports halls, stadiums and public spaces were seen for this purpose. In order to smooth the coverage of the city of Douala, sports spaces of all the districts were taken into account.

\section{The Population of the Study}

The studied population was constituted of practitioners of physical activity and sport of the city of Douala who attended sporting places during the period of thestudy. Following this study, any person practicing a sporting activity, sexually active and willing to participate in the study were included. Persons aged under18 and those who had been carrying out physical and sport activities for more than twelve months were not included in this study. To carry out this study properly, a consecutive sampling technique was used with a convenient sample size. The size of the sample had been arrested by convenience.

\section{Data Collection}

Data collection was carried out by way of an autoestablished questionnaire containing variables, and piloted on about 30 people. Thus, observed dysfunctions had been corrected, to give way to a questionnaire better suitedto the requirements of this study. This questionnaire in the end relied on 27 issues. It was addressed to persons practicing at least one physical activity or sport. Beforehand, conversations were organized discreetly. The interviewees were approached, either in sports halls, or in public areas equipped for that purpose, taking into account their sensitivity. These interviews allowed a briefing to be made on the contents of the study by taking out its anonymous character, to present to the interviewed its merits in the contribution on the harmony of couples, the health of the population, and the improvement of the sexual life of the latter. Subsequently the consent of the interviewed through the signature of a consent form provided for this purpose, was required by the investigator. The filling of the questionnaire began immediately, taking into account the intellectual capacities of the interviewed. Whenever it was necessary, the interviewees were assisted either by filling of the questionnaire or byensuringthat the instructions of the questionnaire were respected. The filling of the questionnaire took place between ten to fifteen minutes.

This data collection was looking for several types of variables:

The dependent variable was the quality of the sexual activity. It was measured using the following parameters:

- The frequency of sexual intercourse (i.e. number of intercourse a week (Avs B)

- The sexual performance (the duration of the refractory period during which we remain insensitive to external stimuli and the duration of an erection (A vs B).The refractory period corresponded in this study at the time of recovery between two successive intercourses[12]. The cycle of the female sexual response being different from that of men by the multiple orgasms that the women can have during or after sexual intercourse. This study as regards to woman dwelt on the duration of excitation evaluated by the latter [13].

The independent variables among which the sociodemographic data of the practitioner of physical activity, practitionerof sport or competitive sport (CS) included age, sex, profession, marital status, religion and the number of children. Data related to the sports profile of the participants was also collected. This included the practice discipline, the frequency of physical activity and the level of physical activity.It was suggested to the participants to respond to the questionnaire of Ricci and Gagnon to assess their level of physical activity. This questionnaire classifies subjects as inactive, active and very active following their respective scores: < 15 points; between 15 to 32 points; and $>32$ points [14]. 


\section{International Journal of Science and Research (IJSR) \\ ISSN (Online): 2319-7064 \\ Index Copernicus Value (2013): 6.14 | Impact Factor (2015): 6.391}

Data Analysis

Data were recorded and processed using EpiInfo 7 and Excel 2007 software. Data were then analyzed using the XLStat 7.5.2 software. The quantitative variables were presented on mean \pm standard deviation, the qualitative variables in numbers and percentages were presented in parentheses. In bivariate analysis, the comparison between qualitative variables was performed using Chi 2 test and the exact probability of Fisher was determined in the case of dichotomous variables. Differences were considered significant at $\mathrm{p}<0.05$. In multivariate analysis, logistic regression test was used to establish the relationship between the dependent variable which is the improvement of sexual activity and the explanatory variables. The variables used in the logistic regression model were those with $\mathrm{p}<0.2$. The Odd ratio and its 95\% confidence interval were determined to quantify the association between the improvement of sexual activity and the various explanatory variables in the model.

\section{Ethical Considerations}

Informed consent, through the signing of a consent form was required for all those who took part in this study. This work has received the endorsement of the National Ethics Committee, through the Faculty of Medicine and Pharmaceutical Sciences ofthe University of Douala. It should also be noted that various authorizations of research were obtained from officials of the facilitiessolicited for this work. The operations took place following the strict respect of ethics and medical deontology.

\section{Results}

The socio-demographic characteristics of the interviewees

A total of 370 subjectswere included in the study, 303 (81.8\%) men and 67 (18.1\%) women witha sex ratio M/Wof 4.52. The rate of refusal of participation was $75 \%$ for women against $14 \%$ for men. The meanage of the subjects was $30.1 \pm 7.7$ years with extremes of 18 and 65years. The most represented age groups were those under 25 years and between 25-35 years, respectively 103 (27.8\%) and 189 (51.08\%). Regarding marital status, singles were the most representative respectively 244 (65.9\%).Students and pupilsrepresented the largest number that is 198 (53.5\%). Among the subjects, 132 (35.6\%) were parents of at least one living child and it was also noted a majority wereChristians, 352 (95.1\%)

\section{The data related to the sport profile}

Among the 370 subjects, 246 (66.4\%) practiced a physical activity for health and 124 (33.5\%) practiced competitive sports.Regarding the usual level of activity of the subjects, the score of Ricci and Gagnon had allowed to qualify 357 (96.4\%) as active and $13(3.5 \%)$ as very active. Among the age groups, it was noted that the more than 45 years age group had a sporting session that lasted at most 2 hours, with a majority which had a session that lasted at most $1 \mathrm{~h}$. This corresponds to $31.2 \%$ for a session of $1-2 \mathrm{~h}$ and $68.7 \%$ for a $30 \mathrm{~min}$ to $1 \mathrm{~h}$ session

\section{The population according to sex and discipline}

Among the studied population, the interviewed practiced at least one discipline either physical and sport activity (PSA)or competitive sports (CS).Among practitioners of PSA, it was noted on one hand more women than men who practiced fitness $(\mathrm{P}<0.005)$, dance $(\mathrm{P}=0.02)$. On the other hand, more men than women practiced jogging $(\mathrm{P}=0.02)$ as well as football $(\mathrm{P}<0.005)$. Whereas in $\mathrm{CS}$, women practiced mostly dance $(\mathrm{P}<0.005)$. Men were more engaged in football $(\mathrm{P}=0.04)$ (table I).

\section{Table I:}

Distribution of interviewees by sex and discipline in their categories

\section{Changes in the observed sexual habits.}

Changes in sexual habits concerned the number of sexual intercourse and sexual performance. Regarding the number of sexual intercourse, a decrease was noted in men compared to women $(\mathrm{P}=0.02)$. No difference was observed with regard to sexual performance (table II)

Table II: Changes in sexual habits following the gender

Depending on the age group, an improvement in the number of sexual intercourse wasnoted in the age group25-35years $(\mathrm{P}$ $=0.005$ ). Regarding the performance, there was a significant improvement in the age group25-35years and among those under 25 years $(\mathrm{P}=0.008)$ (table III).

\section{Table III: Changes in sexual habits according to the age}

No change in sexual habits had been observed, whether among those practicing PSAand those practicing CS.Regarding marital status, the results in changes in sexual habits observed showed no statistically significant difference.The results were also concerned the differences between parents and non-parents. Also, 105 (44.1\%) participantshaving no child declared to have known an improvement in the number of sexual intercourse since the beginning of sports activities, against 42 (31.8\%) which had at least one child $(\mathrm{P}=0.02)$. No difference was noted for the sexual performance in this case.From the category of exercise, we noted an improvement in the refractory time in practicing PSA $(\mathrm{P}=0.03)$. On thecontrary, there was a decrease of that time in male subjects $(\mathrm{P}=0.01)$.

\section{Duration of the erection in menand the excitement in women}

The rate of participants having revealed an improvement of the sexual activity was calculated by category and gender.Overall, there was an increase in the duration of the erection and arousal respectively for women and men and for all categories. This improvement was more significant for males $(\mathrm{P}=0.04)$.

\section{Factors independently associated to the improvement of sexual activity}

The multivariate regression model used for variables with a $\mathrm{p}<0.2$ presented a correlation between the age group (35-45) [95\% CI; OR = 0.37 - 0.87; $\mathrm{P}=0.002]$, male [95\% CI; OR = 1.02-3.33. $\mathrm{P}=0.004]$ and improved sexual activity (table IV). 


\section{International Journal of Science and Research (IJSR) ISSN (Online): 2319-7064 \\ Index Copernicus Value (2013): 6.14 | Impact Factor (2015): 6.391}

Table IV:Factors independently related to changes in sexual activity

\section{Discussion}

This study allowed us to make an analysis of the influence of physical activity on sexual activity amongstthe practitioners of PSA and CS of the city of Douala.

In the end, 370 subjects were included in this study. The reduced workforce that represents women would be justified by the fact that, in front of topics such as sexuality, women are more modest than men; in addition to that the arguments of culture and the Africantradition according to which sexual activity for women is not to be spokento the first comer [5]. The minimal age of 18 years required in this study is understandable by the fact that it would be more convenient to talk about sexuality with grown-up people. This goes in straight line with the work of researchers from the University of Chicago who had interviewed 500 women aged between 18 to 45 years [7].

Speaking about the marital status, it had not been taken into account in most studies.In this present one, it was necessary to know whether if the obligations of the couple did not have an additional influence on a possible outcome in terms of change of habits and/or sexual capacity. The results show no significant difference. The study of the Massachusetts researchers arrived at the same conclusion [15].

The parameter - fumber of children"was taken into account to assess the influence that can have the presence of a child in the sex life of a couple. The results showed in this sense a statistically significant difference in the case of improvement where 105 (44.1\%) participants who had no child claimed to have noticed an increase in their number of sexual intercourse against 42 (31.8\%) who had at least one child. This could be justified by the fact that the presence of a child contributes in a decrease of sexual desire or libido particularly in lactating women. In this case, this decrease is due to the secretion of prolactin which stimulates the production of breast milk, inhibiting the secretion of desire hormones in women,in particular, estrogens [16]. Moreover the presence of a child is an additional concern of the parents which can make them move away from the sexual environment, to worry about more 'important' issues [17].

The recommendations of current physical activity necessary to reduce the risk of chronic diseases in general and cardiovascular in particular, have been defined by WHO for adult as follows: "practice any physical activity that can be carried out, of moderate intensity (comparable to walking), at a frequency of 6 - 7 times per week, over a period greater than or equal to 30 minutes a day on one or several occasions» [18].In a general context, the participantshad a normal level of activity that classified them as active for the majority -357 (96.4\%) and very active -13 (3.5\%)). The comparison of these results with the recommendations of WHO suggests that the studied population,in its own way,met the conditions of a physical activity needed to reduce the risk of chronic diseases in which erectile dysfunction ranks. This constitutes a good point for their physical activity.
Regarding the age group more than 45 years, no improvement in the number of sexual intercourse had been declared. This age group practiced sport mostly over a period of 30 minutes to one hour.The results of the study conducted by researchers at the University of California with 95sedentary men aged on average 48years old, healthy, trained four times a week and 60 minutes per session at an intensityrepresenting up to $80 \%$ of their maximum heart capacity, however revealed that these men had an increase of $30 \%$ of their sexual relations [19]. The lack of increase in the number of intercourse in subjects aged more than 45 years could be justified by the fact that they have a lower session time than that stated in the study above.The rate of increase of the refractory period is on average higher among practitioners of health sport than in sportsmen. This would be justified by the fact that excessactivity plays an anaphrodisic role by reducing the production of testosterone or hormone of desire [20].

The rate of increase of the duration of arousal in women was $58 \%$, comparable to the results of the survey conducted at Pepperdine University in Los Angeles on 8000 women. It showed that $34 \%$ of these women reported having a more satisfying sex life since they were exercising and 89\% claimed that they had more confidence in their sexual abilities [7]

The regression model allowed us to highlight the factors that influence sexual activity regardless of other factors. These are: the 35-45 age groups and the male sex. Concerning the age group, this improvement could be the fact that at this age, subjects are more resistant to physical and sport activities and as such are likely to better benefit from the influence of the intensity of these activities [21]. On the same momentum, the quality of the sexual improvement which is globally more noticeable among men may be due to the greater resistance of men in physical and sports activities.This predisposes them definitely to a better state of health [20].

At every stage of life, health is characterized by complex interactions between multiple socio-economic factors, in interdependence with the physical environment and individual behavior. These factors are referred to as the determinants of health. They do not act alone; it is the combination of their effects that influences the state of health [22]. Sport and physical activity beyond the prevention of chronic diseases which they provide and the sexual activity that they improve, present themselves as elements of individual behavior susceptible to positively influence the health status. Hence the need of their permanent practice at all ages [23].

This study had known limits. The reluctance of the population to participate in the study, because of the sensitive nature of sexuality in Africa, ledto a reduced sample.Furthermore, the fact that there were no elements which could assess the energy expenditure of each individual after his workout could be a bias in the analysis of the results. 


\section{International Journal of Science and Research (IJSR) \\ ISSN (Online): 2319-7064 \\ Index Copernicus Value (2013): 6.14 | Impact Factor (2015): 6.391}

\section{Conclusion}

The practice of physical exercise comes to revitalize the entire body and compensate for physiological, mental and physical health problems. Its effect on sexual activity presented in this study, was to assert that it has a positive influence on the quality of sexual activity. The results of this work indicate that its practice is likely to enhance sexual activity, especially among men and those aged 35 to 45 years. Because of its positive effect on the prevention of chronic diseases and its influence on certain determinants of health in general, its practice must be widely encouraged.

\section{Conflict of Interest}

The authors reported no conflict of interest

\section{Contribution of Authors}

All authors have designed the study and drafted the manuscript. EN started the study and made major contributions to the design of the study and the statistical analysis. All the authors contributed to the writing of the manuscript and approved the submitted version of the manuscript

\section{References}

[1] Huang R, Ho SY, Lam TH. Physical activity and constipation in Hong Kong adolescents.Plos one 2014;9(2):1-5.

[2] Margot AK, Marieke WV, Mai JMC, Marijke HR. Determinants of physical activity an exercise in health older adults: a systematic revew. International journal of behavioral nutrition and physical activity Act 2011; 8:142.

[3] Ridley K, Ainsworth BE, Olds TS. Development of a compendium of energy expenditures for youth.IntJBehavNutrPhys Act 2008;5:45.

[4] Maïza D. Physiologie du rapport sexuel. Dans :Lopès $P$, Poudat FX. Manuel de sexologie. Paris: Elsevier Masson SAS ; 2007.p.23-34.

[5] Fadibo P. Santé phalliqueetconjugalité au NordCameroun (XIXè-XXème siècles). Nordic Journal of African Studies 2012;21(2):75-94.

[6] De SoutoBarreto P, Ferrandez AM, Saliba-Serre B. Questionnaire d'activité physique pour les personnesâgées (QAPPA): validation d'un nouvel instrument de mesureen langue française. Sci Sports 2010;26:11-8.

[7] Chevalier R. L'exercice, c'est bon aussi pour la libido. (enligne)

http://kinesante.pearsonerpi.com/2013/08/30/lexercicecest-bon-aussi-pour-la-libido/. (Consulted on the 05/12/2014).

[8] Rosenberg DE, Norman GJ, Wagner N, Patrick K, Calfas KJ, Sallis JF. Reliability and validity of the Sedentary Behavior Questionnaire (SBQ) for adults. J Phys Act Health 2010;7:697-705.

[9] BitaFouda AA, Lemogoum D, Owona Manga J, Dissongo JII, Tobbit R. Epidémiologie de l'obésitéen milieu du travail à Douala, Cameroun. Rev Med Brux 2012;33:131-7.

[10]Epacka M, Mandengue SO, Belle Priso E, MoumbeTamba S, Ahmadou, BitaFouda A. Dépistage des maladies cardiovasculaires chez des étudiants de l'Université de Douala et influence des activités physiques et sportives. Pan Afr Med J. 2012;11 (4):7782.

[11] Kujala UM. Evidence on the effects of exercise therapy in the treatment of chronic disease. $\mathrm{Br} \mathrm{J}$ Sports Med 2009;43:550-5.

[12] Frei A, Williams K, Vetsch A, Dobbels F, Jacobs L, Rudell K, et al. A comprehensive systematic review of the development process of 104 patient-reported outcomes (PROs) for physical activity in chronically ill and elderly people.HealthQual Life Outcomes 2011;9:116.

[13] Gimeno-Santos E, Frei A, Dobbels F, Rudell K, Puhan MA, Garcia-Aymerich J, for the PROactive consortium. Validity of instruments to measure physical activity may be questionable due to a lack of conceptual frameworks: a systematic review. Health Qual Life Outcomes 2011;9. [doi:10.1186/1477-7525-9-86]

[14] Association Françaised'Etudeet de Recherchesurl'Obésité (AFERO). Questionnaire pour évaluer niveauhabitueld'activitéphysique.http://www.apasante.f r/wiki/_media/questionnaire_ricci_et_gagnon.pdf (consulted on thee 09 octobre 2014)

[15] Frappier J, Toupin I, Levy JJ, Aubertin-Leheudre M, Karelis AD. Energy expendury during sexual activity in young heathlycouples.Plos one, 2013 ; DOI: 10.1371 /

[16] Cour F, Droupy S, Faix A, Methorst C, Giuliano F. Anatomie et physiologie de la sexualité. Association françaised'urologie.ProgUrol, 2013;23(9):547-61.

[17] Bunzl M, Mullen S. A self-report investigation of two types of myotonic responses during sexual orgasm. J Sex Res 1974;10:10-20.

[18] OrganisationMondiale de la Santé (OMS). Recommandationsmondialessurl'activité physique pour la santé. OMS, Genève, Suisse 2010.

[19] Ortigue S, Bianchi-Demicheli F, Patel N. Neuroimaging of love: fMRI Meta-analysis evidence toward new perspectives in sexual medicine. $\mathrm{J}$ Sex Med 2010;7:3541-52.

[20] Salonia A, Giraldi A, Chivers M, Georgiadis J, Levine $\mathrm{R}$, Maravilla $\mathrm{K}$ et al. Physiology of women's sexual function: basic knowledge and new findings. J Sex Med 2010;7:2637-60.

[21] Giraldi A, Levin RJ. Vascular physiology of female sexual function. In: Goldstein I, Meston C, Davis S, Traish A, editors. Women's sexual function and dysfunction: study, diagnosis and treatment London: Taylor \& Francis; 2006:174-180.

[22] Ainsworth BE. How do I measure physical activity in my patients? Questionnaires and objective methods. Br J Sports Med 2009;43:6-9.

[23] Williams K, Frei A, Vetsch A, Dobbels F, Puhan MA, Rudell K. Patient-reported physical activity questionnaires: a systematic review of content and format. Health Qual Life Outcomes 2012;10:28. 


\section{International Journal of Science and Research (IJSR) \\ ISSN (Online): 2319-7064}

Index Copernicus Value (2013): 6.14 | Impact Factor (2015): 6.391

Table I: Distribution of interviewees by sex and discipline in their categories

\begin{tabular}{|c|c|c|c|c|c|c|}
\hline & \multicolumn{2}{|c|}{ CS (N=124) } & \multicolumn{3}{c|}{ PSA (N=246) } & \\
\hline & Female & Male & $\mathrm{p}$ & Female & Male & $\mathrm{p}$ \\
\hline Fitness & - & - & - & $25(55.5 \%)$ & $11(5.4 \%)$ & $<0.0001$ \\
\hline Jogging & - & - & - & $10(22.2 \%)$ & $18(8.9 \%)$ & 0.02 \\
\hline Dance & $10(45.4 \%)$ & $10(9.8 \%)$ & $<0.0001$ & $3(6.6 \%)$ & $1(0.5 \%)$ & 0.02 \\
\hline Basketball & $2(9.09 \%)$ & $18(17.6 \%)$ & 0.5 & $0(0.0 \%)$ & $15(7.4 \%)$ & 0.1 \\
\hline Football & $2(9.09 \%)$ & $33(32.3 \%)$ & 0.04 & $7(15.5 \%)$ & $156(77.6 \%)$ & $<0.0001$ \\
\hline Athletics & $2(9.09 \%)$ & $13(12.7 \%)$ & 0.9 & $2(4.4 \%)$ & $1(0.5 \%)$ & 0.1 \\
\hline Autres & $7(31.8 \%)$ & $26(25.4 \%)$ & 0.7 & $5(11.1 \%)$ & $22(10.9 \%)$ & 0.8 \\
\hline
\end{tabular}

CS: competitive sports, PSA: physical and sport activity

Table II: Changes in sexual habits following the gender

\begin{tabular}{|l|c|c|c|c|c|}
\hline \multicolumn{2}{|c|}{} & Female N(\%) & Male N(\%) & Total & P \\
\hline \multirow{3}{*}{ Sexual intercourse } & Increase & $17(25.3)$ & $67(22.1)$ & $84(22.7)$ & 0.6 \\
\cline { 2 - 6 } & Decrease & $2(2.9)$ & $41(13.5)$ & $43(11.6)$ & 0.02 \\
\cline { 2 - 6 } & No changes & $48(71.6)$ & $195(64.3)$ & $243(65.6)$ & 0.3 \\
\hline Sexual performance & Increase & $20(29.8)$ & $127(41.9)$ & $147(39.7)$ & 0.09 \\
\cline { 2 - 6 } & Decrease & $12(17.9)$ & $51(16.8)$ & $63(17.03)$ & 0.9 \\
\cline { 2 - 6 } & No changes & $35(52.2)$ & $125(41.2)$ & $160(43.2)$ & 0.1 \\
\hline
\end{tabular}

Table III: Changes in sexual habits according to the age

\begin{tabular}{|c|c|c|c|c|c|c|}
\hline & & $\begin{array}{c}<5 y e a r s \\
\mathrm{~N}(\%)\end{array}$ & $\begin{array}{c}25-35 y e a r s \\
\mathrm{~N}(\%)\end{array}$ & $\begin{array}{c}35-45 y e a r s \\
\mathrm{~N}(\%)\end{array}$ & $\begin{array}{c}>45 y e a r s \\
\mathrm{~N}(\%)\end{array}$ & $\mathrm{P}$ \\
\hline \multirow{3}{*}{ Number of sexual intercourse } & Increase & $17(16.5 \%)$ & $56(29.6 \%)$ & $11(17.7 \%)$ & $0(0.0)$ & 0.005 \\
\cline { 2 - 7 } & Decrease & $5(4.9 \%)$ & $22(11.6 \%)$ & $12(19.4 \%)$ & $4(25.0 \%)$ & 0.01 \\
\cline { 2 - 7 } & No change & $81(78.6 \%)$ & $111(58.7 \%)$ & $39(62.5 \%)$ & $12(75.0 \%)$ & 0.006 \\
\hline \multirow{3}{*}{ Sexual performance } & Increase & $44(42.7 \%)$ & $85(45 \%)$ & $15(24.2 \%)$ & $3(18.8 \%)$ & 0.008 \\
\cline { 2 - 7 } & Decrease & $14(13.6 \%)$ & $28(14.8 \%)$ & $18(29.8 \%)$ & $3(18.8 \%)$ & 0.04 \\
\cline { 2 - 7 } & No change & $25(43.7 \%)$ & $76(40.2 \%)$ & $29(46.8 \%)$ & $10(62.5 \%)$ & \\
\hline
\end{tabular}

Table IV: Factorsindependentlyrelated to changes in sexualactivity

\begin{tabular}{|c|c|c|c|c|}
\hline & & OR & CI at 95 de of OR & $\mathrm{P}$ \\
\hline \multirow[t]{4}{*}{ Age group } & $25-35$ years & Réf & & \\
\hline & $<25$ years & 0.8 & $0.50-1.42$ & 0.5 \\
\hline & 35 - 45 years & 0.3 & $0.16-0.87$ & 0.02 \\
\hline & $\geq 45$ years & 0.3 & $0.07-1.38$ & 0.1 \\
\hline \multirow[t]{2}{*}{ Gender } & Female & Réf & & \\
\hline & Male & 1.8 & $1.02-3.33$ & 0.04 \\
\hline \multirow[t]{4}{*}{ Marritalstatus } & Single & Réf & & \\
\hline & Concubinage & 2.5 & $0.59-11.45$ & 0.2 \\
\hline & Maried & 1.2 & $0.54-2.89$ & 0.6 \\
\hline & Free Union & 1.2 & $0.63-2.27$ & 0.6 \\
\hline \multirow[t]{2}{*}{ Number of children } & None & Réf & & \\
\hline & At least 1 child & 0.8 & $0.44-1.59$ & 0.6 \\
\hline \multirow[t]{2}{*}{ Jogging } & No & Réf & & \\
\hline & Yes & 0.6 & $0.23-1.78$ & 0.4 \\
\hline \multirow[t]{2}{*}{ Athletics } & No & Réf & & 0.3 \\
\hline & Yes & 1.7 & $0.63-4.62$ & \\
\hline \multirow[t]{2}{*}{ Category } & PA of health & Réf & & \\
\hline & Sports & 1.01 & $0.62-1.66$ & 1.0 \\
\hline
\end{tabular}

